\title{
Effect of blue and red radiation on cycling stomata of bean ${ }^{1}$
}

\author{
P. A. M. Hopmans \\ Department of Horticulture, Agricultural University, Wageningen, the Netherlands
}

Received: 30 March 1973

\section{Summary}

Differences in the effect of blue and red radiation of low radiant flux density on sustained stomatal cycling were studied to extend general information on effects of light colour on stomatal opening. Stomatal behaviour in a constant environment was observed indirectly by recording the difference between leaf and air temperature.

In irradiation with equal radiant flux densities of $1.75 \mathrm{~W} \mathrm{~m}^{-2}$ and with equal estimated absorbed quantum flux densities of $0.73 \mathrm{nE} \mathrm{cm}^{-2} \mathrm{~s}^{-1}$ of both colours, cycling was more rapid and peak-to-trough differences were smaller in red than in blue radiation. Blue radiation from below caused more rapid cycling with larger peak-to-trough differences than radiation from above. In red radiation the direction of radiation had a much smaller influence on period and peak-to-trough difference.

To explain these qualitatively different effects of both colours on cycling stomata, the hypothesis is proposed that blue light increases the osmotic pressure in the guard cells more effectively than red light. In blue light the permeability for water transport of the guard cell membranes is lower than in red light.

\section{Introduction}

Stomatal cycling is called the phenomenon that stomata of whole leaves or whole plants continuously alternate their openings with more or less constant periodicity and amplitude. It has received increased attention during the last few years (Barrs, 1971).

The effect of environmental factors on sustained cycling of bean plants was studied by Hopmans (1971) for the factors radiation flux density, carbon dioxide concentration and temperature. It was found that radiant flux densities beyond a certain level between 16 and $34 \mathrm{~W} \mathrm{~m}^{-2}$ of white light on the upper side of the leaves, did not affect the period of cycling. Below that level, especially in the range below $2 \mathrm{~W} \mathrm{~m}^{-2}$, the period of the cycles increased and the peak-to-trough difference decreased at decreasing radiant flux density. Also temperature and carbon dioxide concentration markedly affected the characteristics of sustained cycling.

The spectral composition of light is known to have a specific influence on steady (= non-cycling) stomatal opening. It is generally agreed that blue light is much more effective in producing and maintaining stomatal opening than red light, whereas other light colours are even less effective than red (Mouravieff, 1958; Karvé, 1961; Kuiper, 1964; Mansfield \& Meidner, 1966). The effects of environmental factors on stomatal

1 Publication 383, Laboratorium voor Tuinbouwplantenteelt, Landbouwhogeschool, Wageningen, the Netherlands. 
cycling (Hopmans, 1971) were different from those observed on steady stomatal opening and provided new information about the physiological mechanism of stomatal opening. The next step in this approach is the study of the influence of light colours on stomatal cycling. In the present study an analysis is presented of the characteristics of sustained cycling in blue and red radiation.

\section{Materials and methods}

\section{Plants}

Intact bean plants, Phaseolus vulgaris cv. 'Vroege Wagenaar', 4 to 6 weeks old, were used. The primary leaves were fully expanded and the apices of top and lateral shoots were removed regularly. The plants were grown on nutrient solution. After an initial period of two weeks in the greenhouse, they were placed in a climate room with $24{ }^{\circ} \mathrm{C}$ air temperature, $75 \%$ relative humidity in white light (fluorescent tube Philips TL 55) of $35 \mathrm{~W} \mathrm{~m}^{-2}$. A 16-hour daily light period was given at the same period of the day as during the experimental treatment.

\section{Experimental conditions}

The experiments were carried out in a large ventilated room without short periodic fluctuations of air temperature and humidity. The primary leaves of six plants, fixed in one horizontal plane, were irradiated and observed simultaneously.

Blue radiation was obtained from blue fluorescent tubes Philips TL 18, covered by blue cinemoid colour filter No 20 , and red radiation from red fluorescent tubes Philips TL 15.

The plants were shielded by plexiglass from long-wave radiation emitted by the tubes, whereas the total amount of heat produced by the tubes was equal in all treatments by installing a constant number of tubes and screening to the desired irradiation flux density.

For irradiation from below the tubes were installed underneath the plants.

\section{Irradiation}

For the installation of the radiant flux densities a flat selenium cell photometer was used. The photometer had been calibrated with a thermopile (solarimeter) for the

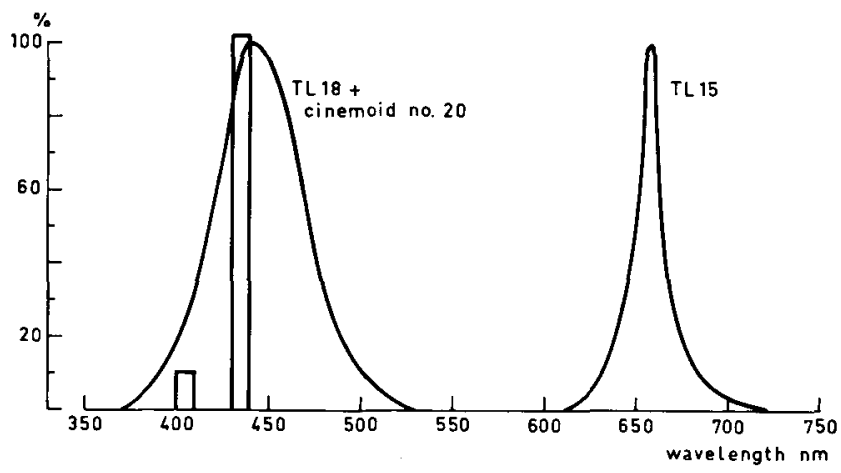

Fig. 1. Relative spectral energy distribution of blue and red irradiation. 
light colours used. With the spectral emittance curves of the fluorescent tubes and the spectral transmission curves of the cinemoid filters, the spectral energy distribution of the radiation used was calculated (Fig. 1).

The calculation of the radiant flux densities required for equal absorbed quantum flux densities by the leaves was performed using the method described by Gaastra (1959). From the curves presented in Fig. 1, the spectral distribution of estimated absorbed radiation was derived and the relative quantum fluxes per spectrum band of $20 \mathrm{~nm}$. For equal absorbed quantum flux density of $0.73 \mathrm{nE} \mathrm{cm} \mathrm{c}^{-2} \mathrm{~s}^{-1}$ the radiation flux densities thus calculated and installed were $2.13 \mathrm{~W} \mathrm{~m}^{-2}$ of blue and $1.51 \mathrm{~W} \mathrm{~m}^{-2}$ of red radiation.

\section{Measurement}

Stomatal behaviour was determined indirectly from the course of temperature difference between leaf and air by thermocouples.

In case the difference does not exceed 2 to $3{ }^{\circ} \mathrm{C}$ its relation with stomatal diffusion conductivity is approximately linear at constant environmental conditions and moderate wind speed (Hopmans, 1971).

The leaves were fixed in a horizontal position. One junction of the thermocouples used was pressed against the not directly irradiated side of the leaf, whereas the other junction was in the air about $5 \mathrm{~cm}$ from the leaf.

\section{Results}

Effect of blue and red light on period and peak-to-trough difference

In the experimental position, white light of $3.5 \mathrm{~W} \mathrm{~m}^{-2}$ with photoperiods of 16 hours was applied during several days and subsequently the photoperiod was started with red or blue light. When cycling was sustained, the light colour was changed at about the middle of the photoperiod.

Fig. 2 presents an example of sustained cycling in two plants in red succeeded by blue of equal radiant flux density.

From the moment radiation was turned from red to blue, the period of cycling was longer and the peak-to-trough difference (i.e. the periodic stomatal openings) was larger.

Earlier research has shown that in the course of a photoperiod of continuous white

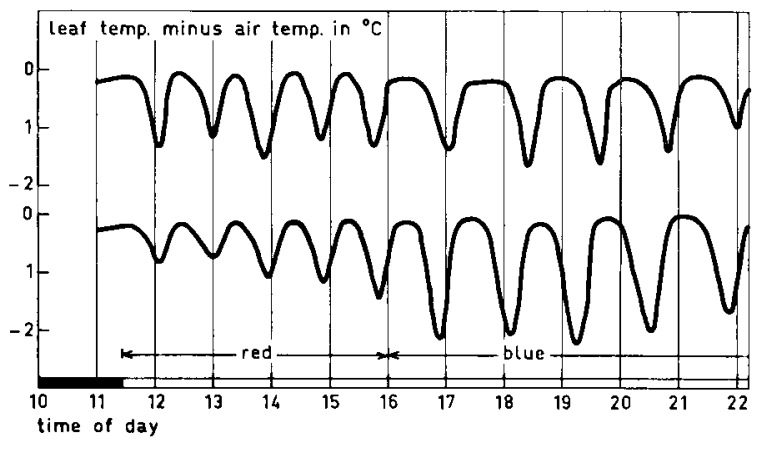

Fig. 2. Course of leaf temperature of two plants with sustained stomatal cycling in red and blue radiation of $1.75 \mathrm{~W} \mathrm{~m}^{-2}$ on the upper side of the leaves. 
Table 1. Mean periods of stomatal cycles in blue and red light immediately before and after changing the colour of irradation with equal radiant flux density and equal absorbed quantum flux density. Significance of difference has been calculated with Student's t-test.

\begin{tabular}{lccccc}
\hline & \multicolumn{1}{c}{$1.75 \mathrm{~W} \mathrm{~m}-2$} & & $0.73 \mathrm{nE} \mathrm{cm-2} \mathrm{s-1}$ \\
\cline { 2 - 3 } \cline { 5 - 6 } & blue & red & & blue & red \\
Number of plants & \multicolumn{2}{c}{13} & & \multicolumn{2}{c}{8} \\
Mean period (min) & 69.7 & 50.8 & & 49.0 & 40.9 \\
P (of difference) & $<0.001$ & & \multicolumn{2}{c}{$<0.001$} \\
\hline
\end{tabular}

light the period of sustained cycling decreases during the first 4 to 6 hours and gradually increases throughout the next 10 hours (Hopmans, 1971, p. 47). Hence, the effect of the light colour on the period of cycling during the second half of the photoperiod would be either spuriously favoured or reduced for blue and red, respectively. For that reason only the data of blue irradiation during the first half and red radiation during the second half of the photoperiod will be presented. Comparisons were made of equal radiant flux densities of $1.75 \mathrm{~W} \mathrm{~m}^{-2}$ and of equal absorbed quantum flux densities of $0.73 \mathrm{nE} \mathrm{cm}$-2 $^{-1}$ of both colours.

Table 1 presents periods observed immediately before and after the transition of the light colour. The differences were clear and statistically significant. In blue radiation the periods were longer than in red.

When peak-to-trough differences in both irradiation colours were compared, as is done in Table 2, those in blue radiation turned out to be significantly larger than in red radiation, both in equal radiant flux density and in equal quantum flux density.

Table 2. Mean peak-to-trough difference of stomatal cycles measured as leaf temperature (in ${ }^{\circ} \mathrm{C}$ ) in blue and red light immediately before and after changing the colour of irradiation with equal absorbed quantum flux density. Significance of difference has been calculated with Student's t-test.

\begin{tabular}{|c|c|c|c|c|}
\hline & \multicolumn{2}{|c|}{$1.75 \mathrm{~W} \mathrm{m-2}$} & \multicolumn{2}{|c|}{$0.73 \mathrm{nE} \mathrm{cm-2} \mathrm{s}^{-1}$} \\
\hline & blue & red & blue & red \\
\hline Number of plants & \multicolumn{2}{|c|}{14} & \multicolumn{2}{|c|}{11} \\
\hline $\begin{array}{l}\text { Mean peak-to-trough } \\
\text { difference }\left({ }^{\circ} \mathrm{C}\right)\end{array}$ & 1.99 & 1.34 & 2.17 & 1.66 \\
\hline $\mathbf{P}$ (of difference) & \multicolumn{2}{|c|}{$<0.001$} & \multicolumn{2}{|c|}{$<0.01$} \\
\hline
\end{tabular}

Irradation from above and from below with blue and red

It is known that radiation influences stomatal opening directly via an activation of a mechanism within the guard cell and indirectly via reducing the carbon dioxide concentration in the substomatal cavity due to photosynthesis in the mesophyll tissue. In hypostomatous leaves direct effects of radiation on stomatal opening will be larger at 
Table 3. Mean period and peak-to-trough difference of leaf temperature during stomatal cycling immediately before and after changing the direction of irradiation with constant flux density. Significance of differences has been calculated with Student's t-test.

\begin{tabular}{|c|c|c|c|}
\hline & \multirow{3}{*}{$\begin{array}{l}\text { Number of } \\
\text { plants }\end{array}$} & Mean period (min) & \multirow{2}{*}{$\begin{array}{l}\text { Mean peak-to-trough } \\
\text { difference of leaf } \\
\text { temperature }\left({ }^{\circ} \mathrm{C}\right)\end{array}$} \\
\hline & & \multirow{2}{*}{$\begin{array}{l}\text { irradiation from } \\
\text { below above }\end{array}$} & \\
\hline & & & $\begin{array}{l}\text { irradiation from } \\
\text { below above }\end{array}$ \\
\hline $\begin{array}{l}\text { Blue } \\
\text { P (of difference) }\end{array}$ & 22 & $53.1<0.001^{76.0}$ & $<0.01^{1.5}$ \\
\hline $\begin{array}{l}\text { Red } \\
\mathbf{P} \text { (of difference) }\end{array}$ & 15 & ${ }^{58.3}<0.01^{66.6}$ & $1.9<0.001^{1.6}$ \\
\hline
\end{tabular}

radiation from below than from above. Indirect effects of radiation on stomatal opening will be smaller depending on the direction of irradiance.

On the plants used in the experiments counts were made of stomatal frequency on upper and lower epidermis. The stomatal frequency on the lower epidermis was about 125 and on the upper epidermis 19 per $\mathrm{mm}^{2}$. The leaves were thus almost hypostomatous. Furthermore Kanemasu \& Tanner (1969) found for bean that stomata of the upper epidermis were less sensitive to light than those of the lower epidermis.

Whether irradiation from above and from below affected stomatal cycling in a different way was studied for blue and red light separately. This was done by comparing the periods and peak-to-trough differences of sustained cycling immediately before and after transition of the radiation source from above to below or vice versa. Radiation flux densities were equal at leaf level from both directions, blue radiation approximately $1.5 \mathrm{~W} \mathrm{~m}^{-2}$ and red radiation $1.1 \mathrm{~W} \mathrm{~m}^{-2}$. Table 3 presents the results as means of periods and of peak-to-trough differences for the plants exhibiting sustained cycling throughout a certain time before and after changing the direction of irradation. For blue radiation the periods were considerably and significantly shorter and the peak-to-trough differences larger when radiation came from below. For red radiation the differences tended to the same direction, but were much smaller and significant.

The effects of blue and red radiation from above and from below can be summarized as follows. In red radiation cycling was more rapid and peak-to-trough differences were smaller than in blue radiation of the same energy flux density and of the same quantum flux density. Blue radiation from below caused more rapid cycling with larger peak-to-trough differences than blue radiation from above. In red radiation the direction of radiation had a small influence on period and peak-to-trough difference.

\section{Discussion}

Increase of radiation flux in the low ranges shortened the period but increased the peak-to-trough difference (Hopmans, 1971, p. 58). Hence, transition of blue light from above to below the leaves had the same effect as increasing it. This suggests that blue light affected stomata during cycling directly in the sense described above. The effects of transition of red light from the upper to the lower side of the leaf suggests that a large part of its effect on stomata was indirect. 
Publications on effects of blue and red light on steady stomatal opening agree that for equal quantum fluxes blue light was considerably more efficient in opening stomata than red light (Mouravieff, 1958; Kuiper, 1964; Mansfield \& Meidner, 1966). Furthermore, the effect of blue light on stonlatal opening turned out to be independent of carbon dioxide.

In case the difference of effects of blue and red light on cycling were merely quantitative, in blue light the period would be smaller and the amplitudes larger than in red light of the same quantum flux density. Both periods and amplitudes were larger in blue light, however. Hence, the effects of blue and red light on cycling stomata differed in a qualitative sense. Presumably the colours activate different parts of the stomatal opening mechanism.

In which respect these two parts of the opening mechanism differ is suggested by the following working hypotheses: blue light increases the osmotic pressure in the guard cells more effectively than red light; in blue the permeability for water transport of the guard cell membranes is lower than in red light. The first part of the hypothesis is in full agreement with the effects found for blue light on steady stomata. The second part was expressed earlier by Raschke (1967) to explain slower stomatal closure in darkness after irradiation with blue light than after irradation with red light. The present results do not add new evidence to this hypothesis, but only corroborate it.

For blue and red radiation the hypothesis will be applied next to stomatal cycling. In blue radiation the opening movement starts at a later stage of increased osmotic pressure of the guard cells than in red radiation due to the lower permeability. Once the opening movement is initiated, it continues and overshoots both by active and by passive opening. Active opening is caused by the high osmotic pressure in the guard cells; passive opening starts and continues as a result of continued active opening (Hopmans, 1971, p. 39). At a certain stage of stomatal opening a rapid 'hydro-active' closure sets in. The wole sequence of events is repeated more intensively and faster at increasing radiation or by bringing the blue light source from above to below the leaf as a consequence of increased radiant flux density on the lower epidermis.

In red radiation the lag of turgor increase behind increasing osmotic pressure is smaller due to the lower permeability to water of the guard cell membranes. Hence, the stomata start their opening movement after a shorter sub-period of lower stomatal opening. As a consequence the passive closure forces remain smaller, facilitating earlier onset of stomatal opening. The rate of increase of osmotic pressure in red radiation being lower, active stomatal opening movement proceeds more slowly. Therefore the passive opening component will be smaller, because the water balance of the neighbouring cells is less affected.

Red radiation from below intensified stomatal cycling only to a small degree as compared with irradiation from above, presumably because red light is less effective in the direct sense in opening stomata and because red radiation affects stomatal opening more indirectly via reduced $\mathrm{CO}_{2}$ concentration in the substomatal cavity.

\section{References}

Barrs, H. D., 1971. Cyclic variations in stomatal aperture, transpiration, and leaf water potential under constant environmental conditions. A. Rev. Pl. Physiol. 22: 223-236.

Gaastra, P., 1959. Photosynthesis of crop plants as influenced by light, carbon dioxide, temperature and stomatal diffusion resistance. Meded. LandbHogesch. Wageningen 59 (13): 1-68.

Hopmans, P. A. M., 1971. Rhythms in stomatal opening of bean leaves. Meded. LandbHogesch. Wageningen 71 (3): $1-86$. 
Kanemasu, E. T. \& C. B. Tanner, 1969. Stomatal diffusion resistance of snap beans. II. Effect of light. Pl. Phy siol. 44: 1542-1546.

Karvé, A. 1961. Die Wirkung verschiedener Lichtqualitäten auf die öffnungsbewegungen der Stomata. Z. Bot. 49: 47-72.

Kuiper, P. J. C., 1964. Dependence upon wavelength of stomatal movement in epidermal tissue of Senecio odoris. Pl. Physiol. 39: 952-955.

Mansfield, T. A., \& H. Meidner, 1966. Stomatal opening in light of different wavelengths. Effects of blue light independent of carbon dioxide concentration. J. exp. Bot. 17: 510-512.

Mouravieff, I., 1958. Action de la lumière sur la cellule végétale. Production de mouvement de l'ouverture stomatique par la lumière des diverses régions du spectre. Bull. Soc. Bot. Fr. 105: $467-475$.

Raschke, K., 1967. Der Einfluss von Rot- und Blaulicht auf die öffnungs- und Schliessgeschwindigkeit der Stomata von Zea mays. Naturwissenschaften 54: 72-73. 